\title{
The Effect of Closed Environment on Psychological Consciousness in Different Social Groups
}

\author{
Xuanshuo Chen* \\ Suzhou Dulwich High School, Suzhou, 215127, China \\ *Corresponding author. Email: xschenvip@163.com
}

\begin{abstract}
The purpose of this study is to explore the psychological and behavioral effects in a closed environment. We consider that in an isolated, closed and extreme environment, it provides a valuable opportunity to experience more stressors than ordinary people's daily life. The increasingly popular psychological symptoms, syndromes, mental disorders and positive health origin effects are considered to be related to various environmental factors. Isolated and closed environment mainly includes submarine environment, remote island environment, ship environment, etc. groups in isolated and closed environment not only have obvious mental health problems, but also their cognitive function is affected. Therefore, it is necessary to study the impact characteristics and mechanism of isolated and closed environment on group cognitive function.

This paper will summarize the previous studies, sort out the effects of isolated and closed environment on individual cognitive functions such as attention, reaction time, memory, abstract generalization ability and comprehension, and look forward to the future research.
\end{abstract}

Keywords: Isolated and closed environment, Cognitive function, Note, Reaction time, memory

\section{INTRODUCTION}

For some special occupational groups, due to shoulder special mission, in special environment, undertake special tasks, long-term facing greater pressure, their mental health problems have attracted people's attention. Due to their confidentiality, they tend to adopt closed or semi-closed management, which affects their communication with the outside world. Most of the communication is within the group, belonging to the communication within the group. This kind of communication requires little communication skills, and the communication is relatively simple. Due to training, duty and all kinds of discipline, they go out to have fewer opportunities, communicate with outside groups, on the one hand, they are learning and mature personality and shaping stage of social rules, on the other hand, most of them are learning is an internal code of conduct and military skills, less exposed to general social interactions, and complex social interaction of exercise very little, As a result, these groups often exhibit their own characteristics and behaviors, and people who do not understand them may even consider them strange. Some groups live in remote areas with inconvenient transportation, limited communication, poor and boring amateur social life, and lack of general social communication[1]. Such working environment is called isolated and closed environment, which is of great significance for the study of the psychology and behavior of groups in these environments.

\section{PSYCHOLOGICAL PROBLEMS EASILY CAUSED BY CLOSED ENVIRONMENT}

\subsection{Anxiety}

Anxiety is an unpleasant emotional experience caused by people's maladjustment to the environment or things. When some newcomers come to the closed environment for the first time, they will have bad emotions such as insomnia and irritability because they are difficult to adapt to the new environment. If they are not dredged in time, the psychological conflicts accumulated for a long time will interfere with the normal activities of the nervous system and make the bad psychology evolve into psychological problems.

\subsection{Depression}

Depression is a psychological phenomenon of depression and anxiety. Depression is characterized by 
sadness, emptiness and a sense of worthlessness. The image description is "living without love" and "feeling like the most useless person in the world". Some people have less outdoor activities and more thinking time after they come to the closed environment due to unsatisfactory work, high work pressure, frustrated life, lovelorn or tense interpersonal relations. These unsolved problems become psychological pressure. There is no place to vent their bad emotions, and depression will appear over time.

\subsection{Fear}

Fear refers to the strong fear of certain things or special situations. Fear is characterized by lack of selfcontrol, irritability, shortness of breath and nausea. In a long-term closed environment, the time to contact nature is relatively limited and fixed. Normal people will have a certain fear of the closed environment itself. In addition, the personnel are relatively concentrated, the activity place is limited, the safe distance between people is reduced, and the private space is deprived. Officers and soldiers are easy to have fear.

\subsection{Resistance}

Conflict psychology is an unpleasant psychological reaction to ideas and things imposed on oneself. The characteristics of conflict psychology are disgust, rejection and resistance. Because some veterans have experienced working and living in a closed environment, the psychological discomfort left more or less before has not been solved in time. When they face this environment again, some potential bad emotions will reappear because of the same environment. These bad emotions may be the recurrence of the previous bad emotions, or they may appear in a new form, but in any case, psychological discomfort is increasing.

\section{STUDY ON THE EFFECT OF MILITARY ISOLATED AND CLOSED ENVIRONMENT ON OFFICERS AND SOLDIERS' COGNITIVE FUNCTION}

\subsection{In the aspect of attention}

The different clinical manifestations of attention disorder in patients with brain injury were summarized, and attention was divided into five types: focused attention, continuous attention, selective attention, metastatic attention and distributive attention. At present, researchers mainly study the impact of military isolated and closed environment on officers and soldiers' distributive attention and focused attention.

\subsubsection{Distributive attention}

The attention distribution instrument produced by the science and education instrument factory of East
China Normal University to measure the attention distribution ability of two types of soldiers guarding the island in far island environment and those in the mainland control group. The results showed that the far island environment had no significant effect on the attention distribution ability of soldiers guarding the island for 5 years, but had a certain effect on the attention distribution ability of soldiers guarding the island for $>5$ years. Someone used the attention distribution instrument produced by the science and education instrument factory of East China Normal University to measure the attention distribution ability of submarine submariners and submarine shore service personnel respectively[2]. It was found that the correct times of submarine phase I and multi-phase non commissioned officers in the dual task test were significantly lower than that of phase I and multi-phase non commissioned officers. The attention distribution instrument produced by the science and education instrument factory of East China Normal University to measure the attention distribution ability of a submarine crew and shore service personnel respectively. The results showed that the number of errors of submarine crew's response to light increased, but the effect did not increase with the increase of military age.

\subsubsection{Focused attention}

The attention concentration tester produced by the science and education instrument factory of East China Normal University to test the target tracking time and times of two types of far island environment soldiers guarding the island and mainland control group soldiers respectively. The results showed that the far island environment had no significant effect on the soldiers' attention concentration ability. Measured the attention concentration ability of submarine crew and submarine shore service personnel respectively by using the attention concentration ability tester. It was found that the number of Miss times of submarine phase I sergeant was more than that of shore service phase I sergeant, the target time of submarine multi-phase sergeant was lower than that of shore service multi-phase sergeant, and the number of Miss times of submarine multi-phase sergeant was more than that of shore service multi-phase sergeant. Used continuous operation test (CPT) to measure the attention concentration ability of the crew one week before, during and after the long-distance voyage mission. It was found that the comprehensive scores of CPT2, 3 and 4 digits of the crew during the voyage were significantly lower than those before and after the voyage. We found that marching at a walking speed of $3.5 \sim 4 \mathrm{~km} / \mathrm{h}$ for $10 \mathrm{~min}$ with a load of $30 \mathrm{~kg}$ in desert environment will lead to increased attention. Used psychomotor vigilance test (PVT) to measure the attention concentration ability of officers and soldiers before and after military survival training. The results showed that the attention concentration ability of officers and soldiers decreased after three months of closed military 
survival training. The attention concentration tester produced by the science and education instrument factory of East China Normal University to measure the attention concentration ability of a submarine crew and shore service personnel respectively. The measurement indicators were target time and miss times. The results showed that the submarine crew missed more times than shore service personnel, and the conscripts showed obvious performance, but there was no difference in Miss times among NCOs[3].

\subsection{Reaction time}

Many studies on astronauts' reaction time show that astronauts' reaction time is not prolonged during space missions, but the number of errors will increase. Tthe neurobehavioral test and evaluation system (nes-c4) be uesed to test the visual simple response under the condition of simulated sinking submarine. There was no statistically significant fluctuation in the visual simple response of subjects before the test and in the 45 days in the cabin. The neurobehavioral core be used to measured combination (WHO-NCTB) recommended by who to test the simple reaction time of some officers and soldiers before and after entering the closed tunnel environment. The results showed that after entering the closed tunnel environment, the fastest reaction time and the average reaction time were significantly prolonged.Gan Jingli et al. sed the two tests of digital fast copy and Chinese character fast comparison in the basic cognitive ability test version 2.0 prepared by $\mathrm{Li}$ Deming to investigate the perceptual speed of pilots, armored soldiers and submarine soldiers[4]. It was found that in the Chinese character fast comparison project, the performance of submarine soldiers was lower than that of pilots and armored soldiers. Others used the attention distribution instrument produced by the science and education instrument factory of East China Normal University to measure the light response time and sound selective response time of the soldiers in the far island and the control group. The results showed that the light response time, the total sound selective response time. There was no significant difference in the ratio of different types of soldiers in each response to sound selection compared with the control group. We used the attention distribution instrument produced by the science and education instrument factory of East China Normal University to measure the sound selective response time of a submarine crew and shore service personnel respectively. The results showed that there was no difference between the sound response time of submarine crew and shore service personnel and the correct number of times, but the number of response errors of submarine multi-stage non commissioned officers was significantly more than that of shore service personnel. Measured the simple response of soldiers in desert environment and general environment, and found that the desert environment had little effect on the simple response time[5].

\subsection{Abstract generalization ability}

Taken the similarity test subscale of Wechsler Adult Intelligence Scale revised in China (WAIS-RC) to test the island guarding soldiers and the mainland control group respectively. The results showed that there was no significant difference between the island guarding soldiers and the mainland control group within 3 years, and the abstract generalization ability of the island guarding officers and soldiers in the fourth year was significantly lower than that of the mainland control group, At the same time, the difference between remote island multi period non commissioned officers and mainland multi period non commissioned officers is close to statistical significance.

\section{IMPACT ON SHIP CREW}

Shipmen are a special group, living in the ship environment for a long time.Because the closed surface ship adopts artificial mechanical ventilation to regulate the air, the living conditions of the crew have been greatly improved. However, due to the long-term work and life in the air-conditioned environment, it also brings some new problems to the physical and mental health of the crew.In order to explore the influence of closed surface ship environment on crew's psychological function and neurobehavior, we tested the crew of closed surface ship with microcomputer neurobehavior evaluation system and symptom checklist 90 (SCL-90), and took the crew of open surface ship as the control[6].

\subsection{Subjects and methods}

The subjects in the test group were 110 members of closed surface ships, with an average age of $22.3 \pm 2.7$ years $(18 \sim 32$ years $)$; The average military age was 4.1 \pm 2.8 years $(2 \sim 13$ years $)$. The subjects in the control group were 110 members of open surface ships, with an average age of $22.9 \pm 2.6$ years $(19 \sim 31$ years $)$; The average military age was $3.8 \pm 2.5$ years $(2 \sim 11$ years).Both groups of subjects were male, with education level above junior middle school.Daily life, work and study are on the ship, but smoking is not allowed in the cabin.

\subsection{Test content}

The neurobehavioral test adopts microcomputer Neurobehavioral Evaluation.

The system (nesc2) was tested according to the standardized method of the World Health Organization who neurobehavioral core test suite (NCTB).The content includes six items: simple reaction time reflecting attention and reaction speed, cursor tracking 
of psychological movement stability, symbol decoding of perceptual memory, digit span and visual retention, hand-held agility of manual operation, etc.

\subsection{Test method}

The ship stops at the wharf and does not go to sea to test the indicators during the mission.SCL-90 questionnaire test: under the same environmental conditions on shore, the crew of closed and open ships adopt the method of group test, and the same subject preaches the guidelines and puts forward requirements for the test, which is scored at 5 levels. Neurobehavioral tests were conducted on two ships. During the test, a brief introduction was given and the subjects were asked to carefully read the introduction on the screen, and then the subjects completed the test independently.

SCL-90 symptom checklist and computerized neurobehavioral evaluation system were used to observe the changes of psychological function and neurobehavior of closed surface ship crew. The test results showed that the score of somatization symptoms of the members of the test group (closed type) was significantly higher than that of the members of the control group (open type). The symbol decoding performance of learning and memory was also significantly lower than that of the control group. This shows that due to the comprehensive effects of noise, vibration, high temperature and humidity, air pollution and other factors on the body of the ship environment, it has brought some effects on the physical and mental health of the crew. According to the test environmental conditions, the environmental conditions of closed ships are not worse than those of open ships, but they have the characteristics of closure. Because human beings have adapted to the changing natural environment in the process of long-term evolution, they have formed a yearning for nature. The crew has lived in a closed ship environment for a long time. They have a sense of closure psychologically and physiologically. They feel that they can't be connected with the external nature. They are in a forced state and have a sense of depression. If you are not satisfied with the indoor state, sometimes you can't even stand it. If the closed ship members reflect hypoxia, the oxygen content in the air is actually within the normal range. Some crew members sometimes show some abnormal behaviors (do not care for public property), which may be related to the crew's psychological state in a closed ship environment. The negative ion concentration in airconditioned rooms is lower than that in naturally ventilated rooms to varying degrees, which is also an important environmental factor. The decrease of air anion concentration has an impact on people's learning and memory and immune functions. The main difference between the two ship environments lies in the different ventilation modes, and the above results cannot be explained by a certain environmental factor. It is reported that the staff working in the air-conditioned environment for a long time have a high incidence of boredom, fatigue, drowsiness, unhappiness, muscle pain and easy to catch a cold. The ship is a special environmental system. The closed surface ship adopts air conditioning and ventilation, and it is best to use negative ion generator at the same time.

\section{CONCLUSION}

In conclusion, this work believes that in an isolated, closed and extreme environment, it provides a valuable opportunity to experience more stress than ordinary people's daily life. The increasing prevalence of psychological symptoms, syndromes, mental disorders, and positive health origin effects are thought to be related to various environmental factors. The isolated and enclosed environment mainly includes the seabed environment, the remote island environment, and the ship environment. The groups in the isolated and enclosed environment not only have obvious mental health problems, but also their cognitive functions are affected.

\section{REFERENCES}

[1] Masato, \& SATO. (1994). Physiological, psychological and behavioral effects of closed spaces. Journal of The Society of Instrument and Control Engineers, 33(12).DOI: https://doi.org/

[2] 10.11499/sicej11962.33.12_1028

[3] Goel, N. , Bale, T. L. , Epperson, C. N. , Kornstein, S. G. , Leon, G. R. , \& Palinkas, L. A. , et al. (2014). Effects of sex and gender on adaptation to space: behavioral health. Journal of Womenl"s Health, 23(11), 975-986.DOI: https://doi.org/10.1089/jwh.2014.4911

[3] KLOCHKO?YULIYAV. (2013). A person in a closed environment as a psychological problem. Psychology in Russia State of the Art, 6(4).DOI: https://doi.org/10.0000/cyberleninka.ru/article/n/aperson-in-a-closed-environme

[4] Gonzaga G C, Campos B, Bradbury T. Similarity, convergence, and relationship satisfaction in dating and married couples[J]. Journal of personality and social psychology, 2007, 93(1): 34. DOI: https://doi.org/10.1037/0022-3514.93.1.34

[5] G[1] Tan, H. W. , Yang, F. , \& Yang, Y. A. . (2011). Effects of closed tunnel environment on the operating worker's behaviors. Hospital Administration Journal of Chinese People's Liberation Army.

[6] Cristiani, E., Piccoli, B. , \& Tosin, A. . (2014). Psychological insights. Springer International Publishing. DOI: https://doi.org/10.1007/978-3319-06620-2_3 